\title{
Mudar o mundo através do poder. Notas críticas às interpretações de Holloway sobre a transição
}

\author{
Angela Lazagna $^{1}$
}

John Holloway ${ }^{2}$ em seu livro, Mudar o mundo sem tomar o poder ${ }^{3}$, apresenta-nos sua reflexão sobre a atual estratégia de superação da sociedade capitalista: “... para destruir o capitalismo sem recair na sua lógica" , faz-se necessária a construção de "...uma sociedade de relações de não-poder..." ${ }^{\text {. }}$. Mas a destruição do capitalismo não pode decorrer, segundo o autor, da conquista do poder do Estado, já que ele representa um tipo de "poder-sobre". Por conseguinte, uma transformação social baseada no "não-poder" e no "anti-poder" não poderia ocorrer através do Estado. Daí o título de seu livro.

Apresentaremos, nesta comunicação, em linhas gerais, a concepção de Estado de Holloway para compreendermos o significado da sua idéia de transformação social. Num segundo momento, faremos uma crítica a essa concepção, entendendo que esse autor, ao compartilhar das teses pertencentes à problemática a qual se pode chamar

1. Doutoranda em Ciência Política pela Universidade Estadual de Campinas (Unicamp) e membro do Centro de Estudos Marxistas (Cemarx).

2. Jonh Hollowayé professor do Instituto de Ciências Sociais e Humanidades da Universidade Autônoma de Puebla, no México. É autor de muitos livros, entre eles In and Against the State, State and Capital (com Sol Picciotto), Zapatista! Reinventing Revolution in México (com Eloína Peláez), La Rosa Roja de Nissan e Marxismo, Estadoy Capital. Publicado pela primeira vez em 2002, na Inglaterra, Mudar o mundo sem tomar o poder já foi traduzido na Espanha, Argentina, Coréia, Alemanha, Turquía e Itália.

3. John Holloway, Mudar o mundo sem tomar o poder. São Paulo, Editora Viramundo, 2002.

4. Idem, ibidem, p. 8.

5. Idem, ibidem, p.32.

Socialismo no século XXI

cadernos cemarx, $\left.n^{0} 3-2006\right) 111$ 
do novo utopismo ${ }^{6}$, nega tanto a importância de se pensar o papel do Estado num processo de transformação social, quanto da prática política das classes sociais nesse mesmo processo.

Em uma coletânea de textos de Holloway ${ }^{7}$, podemos encontrar sua definição de Estado. Para tanto, o autor parte da referência para a construção dessa definição da experiência histórica do "eurocomunismo", que teria trabalhado "... através das formas burguesas [leia-se Estado] para ganhar posições de 'poder' e de 'influência"”, bem como da do Estado de bem-estar social, sinônimo de expansão burocrática e conseqüente aumento da sua presença na vida cotidiana das pessoas ${ }^{9}$. Ao afirmar que "... o Estado não é uma simples instituição, nem um fenômeno que diz respeito a todas as sociedades, mas uma forma historicamente determinada e transitória de relação social" ${ }^{10}$, deduz que a forma Estado é mais uma das formas fetichizadas constitutivas da sociedade capitalista (como a forma mercadoria, a forma dinheiro, etc). É, pois, um equívoco concebê-lo enquanto uma superestrutura, um aparato repressivo, um aparato ideológico que integra as massas ou analisá-lo nos termos de suas funções, pois o importante "... não é unicamente a função que desempenha, mas a forma histórica na qual a desempenha"11.

Por conseguinte, se a forma-Estado está subordinada ao movimento da história, as formas de luta contra as relações capitalistas também devem se transformar ${ }^{12}$. Portanto, o problema para os socialistas consistiria em "... romper, atravessar, ultrapassar a forma estatal como parte integral do ato de esmagar as relações sociais do capitalismo" que tudo fragmenta, ou seja, encontrar a unidade fundamental entre essas formas e restabelecê-las ${ }^{13}$. Holloway ilustra esse argumento referindo-se à crise do chamado Estado de bem-estar social, advertindo que a esquerda deveria se aproveitar da sua

6. Sobre a idéia de um novo utopismo, veja-se Sandra Zarpelon, A esquerda militante e o novo socialismo utópico. Campinas, Unicamp, Dissertação de Mestrado em Ciência Política, 2003.

7. John Holloway. “El Estado y la lucha cotidiana”. In: Marxismo, Estado y Capital. Buenos Aires: Editorial Tierra del Fuego, 1994 [1970].

8. Idem, ibidem, p. 154 (tradução minha, A.L.).

9. Idem, ibidem, p. 141.

10. Idem, ibidem, p. 130.

11. Idem, ibidem, p. 130.

12. Segundo Holloway, idem, p. 120, “O desenvolvimento de novas formas de luta da classe operária é a contrapartida do desenvolvimento do próprio Estado".

13. Idem, ibidem, p. 152.

112 Mudar o mundo através do poder. Notas críticas às interpretações de Holloway sobre a transição 
crise, não através da defesa unilateral da forma-Estado, mas explorando o potencial desestabilizador inerente à retração desse mesmo Estado ${ }^{14}$, já que "as formas modificadas da luta de classes e, portanto, as formas mutantes do processo de constituição das relações políticas burguesas estão criando constantemente novas possibilidades de ação e extinguindo outras, ao irem transformando o significado para a luta de classes das instituições particulares"15. Justamente por esse Estado ser mais uma das formas fetichizadas que constitui a sociedade capitalista, Holloway identifica a crise do capital à crise da forma estatal, pois

A crise, enquanto crise na relação de produção, não somente se estende ao processo imediato de produção, como também ao Estado em suas diversas instâncias. A crise da forma-Estado é tão inevitável quanto a crise da relação capitalista sendo, de fato, uma instância dessa crise ${ }^{16}$.

Mas é no livro Mudar o mundo sem tomar o poder que Holloway, inspirado pela experiência do movimento zapatista e pelas teses desenvolvidas pelo sub-comandante $\operatorname{Marcos}^{17}$, leva às últimas conseqüências sua concepção do Estado. Seria, pois, o atual Estado capitalista "... apenas um nó de uma rede de relações de poder"18 as relações sociais capitalistas não passam de uma relação, mediada pelo dinheiro, entre o empregador e o empregado. Eé justamente essa mediação - o dinheiro - que confere um caráter transnacional ao capitalismo, de modo que

As relações sociais capitalistas nunca foram limitadas pelas fronteiras estatais; (...) A rede de relações sociais em que os Estados nacionais particulares estão imersos é - e foi desde o começo do capitalismo - uma rede global ${ }^{19}$.

Neste sentido, “...o foco da revolução no objetivo de conquistar o poder estatal im-

14. Idem, ibidem, p. 147.

15. Idem, ibidem, p. 153.

16. Idem, ibidem, p. 148.

17. Veja-se sobre esse assunto, Atilio Boron, “A selva e a polis: interrogações em torno da teoria política do

Zapatismo". In: Filosofia política e marxismo, São Paulo, Editora Cortez, 2003.

18. Holloway. Mudar o mundo..., cit., 36.

19. Idem, ibidem, p. 28.

Socialismo no século XXI

cadernos cemarx, $\left.\mathrm{n}^{0} 3-2006\right) 113$ 
plica a abstração do Estado das relações sociais de que é parte"; essa seria a concepção que teria levado as experiências históricas de superação do capitalismo no século XX a um equívoco: o de considerar "...o Estado como motor da mudança radical..." ${ }^{20}$. Por conseguinte, segundo Holloway,

A aparente impossibilidade da revolução no começo do século XXI reflete, na realidade, o fracasso histórico de um conceito particular de revolução, o conceito que identificava revolução com controle de Estado ${ }^{21}$.

A defesa da mudança da sociedade através do Estado pressupõe, segundo o autor, a soberania estatal, pois, mesmo que as mudanças sociais que deveriam ocorrer fossem contempladas, perder-se-iam nesse horizonte estatista ${ }^{22}$. Holloway, sem desconsiderar a tese marxista-leninista - formulada por Marx e Engels a partir da experiência histórica da Comuna de Paris e desenvolvida e radicalizada por Lênin em O Estado e a revolução -, avança na sua argumentação ressaltando que mesmo que Lênin tivesse vislumbrado, para além da conquista do poder, a destruição do velho Estado e a sua substituição por um "Estado dos trabalhadores" e mesmo que, como Trotsky, tivesse vislumbrado a necessidade da internacionalização da revolução,

... continua sendo um fato que, em geral, se considerou a tomada do poder do Estado como um elemento particularmente importante, um ponto central no processo de mudança social, um elemento que exige também uma concentração das energias dedicadas à transformação social. Essa concentração privilegia, inevitavelmente, o Estado como lugar de poder ${ }^{23}$.

A partir dessa constatação, Holloway defende a tese de que lutar contra o Estado não deve significar apropriar-se dele, mas

...trabalhar contra essa forma, desenvolver, através da prática, formas materiais de contra-organização, formas de organização que se oponham às formas

20. Idem, ibidem, p. 28.

21. Idem, ibidem, p. 25.

22. Idem, ibidem, p. 29-30.

23. Idem, ibidem, p. 29.

114 Mudar o mundo através do poder. Notas críticas às interpretações de Holloway sobre a transição 
fetichizadas e fetichizantes da "política" e da "economia" burguesa"24.

De fato, o que importa para o autor é defender que a mudança social se relaciona à construção de uma sociedade na qual não existam relações de poder. "Não se pode construir uma sociedade de relações de não-poder por meio da conquista do poder"25. Mas como isto seria possível? O autor indica, superficialmente, algumas possibilidades:

...participação em "organizações não-governamentais", de campanhas em torno de temas específicos, por meio das preocupações individuais ou coletivas dos professores, dos médicos ou de outras trabalhadoras e trabalhadores que procuram fazer as coisas de uma maneira que não objetive as pessoas, por meio de projetos comunitários autônomos, inclusive as pessoas, por meio de rebeliões de massa e prolongadas como a que ocorreu em Chiapas ${ }^{26}$.

Porém, mesmo sendo assertivo o título do seu último livro, Holloway pergunta-se: "Como se pode mudar o mundo sem tomar o poder? A resposta é óbvia: não o sabemos. Por isso é tão importante trabalhar na resposta, tanto de maneira teórica como prática"27. Mas, ao longo do seu livro, não encontramos uma reflexão teórica de como as práticas sociais postas em marcha pelo ENLZ - Exército nacional de libertação zapatista -, pelo movimento altermundialista, pelas ONGs, estariam caminhando para essa mudança.

A partir dessas considerações, tentaremos sistematizar e apresentar uma crítica a alguns pontos problemáticos das teses defendidas por Holloway.

Primeiramente, nos limitaremos a criticar sua concepção do papel e da função do Estado capitalista.

É importante, pois, ressaltar que é possível perceber em Holloway a influência de uma concepção teórica do Estado que o concebe como separado da "sociedade civil", mesmo que seu intuito seja o de criticar essas teses nas suas mais diferentes

24. Holloway, “El Estado...”, op. cit., p. 154.

25. Holloway. Mudar o mundo..., cit., p. 32.

26. Idem, ibidem, p. 38.

27. Idem, ibidem, p. 40.

Socialismo no século XXI

cadernos cemarx, n-03-2006 115 
versões ${ }^{28}$. Por conseguinte, ao encampar as críticas feitas por muitos daqueles que lutaram contra as experiências do "socialismo real", acaba por conceber a "sociedade civil" como tudo aquilo que não é Estado (sinônimo de despotismo e coerção), ou seja, como a esfera da liberdade ${ }^{29}$. As transformações do capitalismo teriam, pois, imposto uma derrota a uma forma-Estado 'intervencionista', 'ditatorial', de modo que esse Estado passa a não ser mais o lugar privilegiado do poder. Abri-ser-ia, assim, o caminho para a expansão plena dessa "sociedade civil", não mais limitada pelo Estado.

É neste sentido que podemos dizer que a "sociedade civil" é entendida, por Holloway

...como verdadeira miscelânea de grupos e categorias sociais, instituições, identidades e organizações (em especial, as ONGs), e diante da qual, e como se respondesse a um irresistível mecanismo reflexo, o progressista bem-pensante de nosso tempo não hesita e, celebrar esse magnífico florescimento das diversidades, "outridades" e diferenças que nos oferece o capitalismo moderno ${ }^{30}$.

Mas, o grande equívoco dessa atual concepção de "sociedade civil" é o de promover uma ...ensurdecedora exaltação das diferenças e das identidades [que] oculta em sua cacofonia o fato de que há uma dessas "diferenças", a que deriva do pertencimento a uma classe social, que traz na fronte o sinal do pecado ${ }^{31}$.

Com isso não queremos dizer que a atual utilização do termo "sociedade civil" negue a existência das classes sociais; porém, acaba por diluir “...totalmente sua relevância e oculta o conflito estrutural que as opõe, fundido-as na miríade de sujeitos que [a] compõem"32. E é justamente em virtude dessa atual noção de "sociedade civil"

28. Segundo Holloway, idem, p. 28-29, "Conceitualmente, se separa o Estado do complexo de relações sociais que o rodeiam e se eleva-o como se fosse um ator autônomo. Atribui-se-lhe autonomia, se não no sentido absoluto da teoria reformista (ou liberal), pelo menos no sentido de que é considerado como potencialmente autônomo quanto às relações sociais capitalistas que o rodeiam".

29. Boron, “A selva e a polis...", cit. p. 209.

30. Idem, ibidem, p. 210.

31. Idem, ibidem, p. 210.

32. Idem, ibidem, p. 210.

116 Mudar o mundo através do poder. Notas críticas às interpretações de Holloway sobre a transição 
cumprir as funções ideológicas de, por um lado, obstaculizar a percepção da sociedade de classes e da exploração que lhe é inerente e, por outro, de tornar invisível e naturalizado o capitalismo ${ }^{33}$, que se deve tomar muito cuidado com a sua utilização, principalmente se esta for com o intuito de uma crítica à exploração e dominação características do modo de produção capitalista ${ }^{34}$.

A partir desses apontamentos, consideramos importante retornarmos às contribuições originais desenvolvidas por Nicos Poulantzas ${ }^{35}$ para a construção de uma teoria do Estado de tipo capitalista. O Estado, segundo Poulantzas, deve ser considerado como o lugar do político - enquanto superestrutura jurídico-política - e da política - enquanto lugar privilegiado da prática política de classes. É, pois, o lugar desse nível particular do M.P.C. - o nível político. Por conseguinte, entender as especificidades do Estado capitalista é importante para que possamos entender o lugar ocupado e a função exercida por ele no M.P.C., para pensarmos no papel do político na transição socialista e para explicitarmos os limites e equívocos das teses defendidas por Holloway.

Neste sentido, gostaríamos de apontar que Holloway, ao não considerar o Estado de tipo capitalista enquanto uma estrutura jurídio-política do M.P.C., não evidencia que esse Estado ... é o principal fator de coesão das formações sociais divididas em classes, graças à sua função repressiva e a outro aspecto, quase sempre ignorado, que é a sua função ideológica"36.

Podemos considerar que na teoria marxista da história, os "sujeitos" da história são as sociedades humanas dadas que se apresentam como totalidades estruturadas ou modos de produção, de forma que a unidade desses modos de produção é constituída por um tipo específico de complexidade que põe em jogo seu nível econômico e seu nível político ${ }^{37}$. Esses níveis - ou instâncias - estão condicionados por uma relação de implicação recíproca, o que significa que o funcionamento/reprodução de uma instância

33. Ellen Wood, apud, Boron, idem, p. 210.

34. Doravante identificado pela sigla M.P.C.

35. Nicos Poulantzas, Poder político y clases sociales en el Estado Capitalista. Méxixo: Siglo XXI, 1970, 2ª edição. 36. Armando Boito Jr., "O lugar da política na teoria marxista da história”. In: Crítica Marxista, Rio de Janeiro, Editora Revan, no 19, outubro de 2004, p. 76.

37. Isto está relacionado ao conceito ampliado de modo de produção construído por Althusser, cujo objetivo foi a crítica da concepção "economicista" sobre o funcionamento reprodutivo do "todo" social, que encontra guarida no conhecido Prefácio de 59 de Marx. Veja-se: Louis Althusser. A favor de Marx. Rio de Janeiro, Zahar

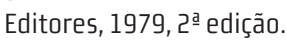

Socialismo no século XXI

cadernos cemarx, n-3-2006 117 
determina e é determinada pelo funcionamento/reprodução da outra instância. Cada modo de produção implica na presença de forças produtivas e relações de produção determinadas, ou seja, apresentam uma organização social da produção e suas correspondentes formas político-ideológicas. É a transformação total dessas instâncias o que promove a transição de um modo de produção a outro.

Neste sentido, Poulantzas, ao analisar o Estado capitalista como lugar da superestrutura jurídico-política, pôde identificar que esse Estado é o responsável pela manutenção das relações de produção através não só da detenção do monopólio da força organizada - o que lhe possibilita utilizar essa força em momentos de instabilidade social para evitar a transformação social - mas também por ser o lugar privilegiado da ação do direito capitalista e do burocratismo - a ele ligado - os quais, no interior das instituições estatais, têm a função de reproduzir, mais ou menos pacificamente, as relações de produção capitalistas. Podemos, a partir dessa análise, compreender os efeitos ideológicos - de isolamento e de unidade - produzidos por esse Estado. O direito, fonte da ideologia contratual da livre compra e venda de força de trabalho - a qual encobre a relação desigualdade entre o capitalista e o trabalhador - apresenta-se como formalmente igualitário, concedendo ao burocratismo, em seu exercício, uma característica de universalidade. É, pois, a burocracia quem recruta, meritocraticamente, seus funcionários, originando uma hierarquia burocrática das competências, cujos membros são, em tese, provenientes de todas as classes. Isto caracteriza esse Estado como o grande representante do povo-nação, de modo que os cidadãos representados por esse Estado passam a não pertencerem a uma classe ou fração de classe determinada e sim, são representados por esse Estado que se coloca acima deles como o grande representante universal da nação. Mas, de fato, o lugar privilegiado do exercício da repressão e da dominação política não é outro que não o aparelho do Estado. É neste sentido que a transição socialista exige uma mudança prévia do Estado para se desenvolver.

Neste ponto, podemos apresentar o segundo momento de nossa crítica às concepções de Holloway. Partimos da constatação de que suas reflexões sobre o Estado capitalista e, conseqüentemente, sua compreensão da transformação da sociedade capitalista negam, terminantemente, a revolução política.

Segundo Holloway, a experiência zapatista cumpriu, até o presente momento, a função de permitir que a esquerda supere a "ilusão estatal", ou seja, uma concepção estadocêntrica da revolução, acusando, pois, a esquerda tradicional e todas as experiências revolucionárias anteriores ao movimento zapatista - Revolução de Outubro de

118 Mudar o mundo através do poder. Notas críticas às interpretações de Holloway sobre a transição 
1917, a Revolução chinesa de 1949 e tantas outras experiências que ousaram superar o capitalismo - de sofrerem, em sua atuação revolucionária e diretriz teórica, dessa ilusão. Em primeiro lugar, é importante dizer que essa posição defendida por Holloway não é nova, pois “...remete a veneráveis discussões [como o debate sobre reforma versus revolução] que animaram o movimento socialista internacional desde meados do século XIX"38.

Em segundo lugar, ao defender que "a existência do político é um momento constitutivo da relação do capital", Holloway defende a inexistência da política antes do capitalismo de modo que esta passa a ser concebida enquanto um mero epifenômeno do capital. O limite dessa idéia é de que a política seria incapaz de se opor ao capital e derrotá-10 ${ }^{39}$.

Frente às essas concepções, o retorno às teses desenvolvidas por Marx, Engels, Lênin, e tantos outros, sobre a centralidade do papel da ditadura do proletariado no processo revolucionário, a partir das experiências históricas como a Comuna de Paris, da Revolução Bolchevique, etc., torna-se imprescindível. Esse retorno nos permite o seguinte questionamento: se o Estado capitalista exerce sua função de manutenção da ordem de uma determinada formação social para a garantia da reprodução do M.P.C. através de suas instituições, como essa função pode ser transformada e suprimida sem a ação política de classe que ocorre através de uma ditadura do proletariado? Neste sentido, as análises da experiência histórica da Comuna de Paris nos trazem uma nova fórmula política: a da necessidade da destruição do aparelho estatal. Essa experiência apontou alguns caminhos para que esse processo de destruição se inicie: através da revolução política, dá-se a supressão do burocratismo; essa supressão acaba por interditar o acesso das classes exploradoras ao aparelho de Estado, eliminando o recrutamento universal e possibilitando que os trabalhadores realizassem as funções estatais - através da representação política de classe -, condição para a sua dominação política. Assim,

Com o novo critério da representação política de classe, é destruído o mito da competência burocrática, baseado na especialização técnica, que funciona como um verdadeiro cordão de isolamento da burocracia em relação ao povo. Essa

38. Atilio Boron, “A selva e a polis...", cit., p. 215.

39. Idem, ibidem, p. ट2z.

Socialismo no século XXI

cadernos cemarx, nํ- - $2006 \quad 119$ 
mudança de critério contribui para subordinar a atividade dos funcionários ao movimento político dos trabalhadores, como pré-requisito para o fortalecimento de sua dominação política ${ }^{40}$.

Também a constituição de um exército revolucionário é a garantia, segundo as experiências da revolução Bolchevique, da Revolução cultural chinesa, etc, da defesa da revolução socialista de uma contra-revolução. Citando o caso da Revolução de Outubro como exemplo, fica claro que sem a organização das massas através do Exército Vermelho e do Partido Bolchevique e da iniciativa dos sovietes, essa experiência revolucionária que inaugura o século XX certamente não teria ocorrido. Logo, se as concepções de Holloway fossem, hipoteticamente, levadas a cabo por aqueles revolucionários, como teria sido possível resistir à guerra imperialista e a todas as tentativas de destruição dessa primeira experiência histórica da contra-revolução capitalista?

Portanto, a postura "antipolítica" que está presente nas teses de Holloway é incompatível com uma proposta de "construção de um mundo novo", pois é justamente essa postura que inviabiliza a transformação social. É neste sentido que Boron ressalta que

Não se constrói um mundo novo (...) se não se modificam as correlações de forças e se derrotam inimigos poderosíssimos. E o Estado é precisamente o lugar onde se condensam as correlações de forças. (...) É o único a partir do qual, por exemplo, os vencedores podem transformar seus interesses em leis e construir um âmbito normativo e institucional que garanta a estabilidade de suas conquistas ${ }^{41}$.

Mas estamos longe de afirmar que é possível a construção, somente a partir da análise dessas experiências históricas, de uma receita da revolução socialista a ser aplicada, incondicionalmente, em todas as formações sociais capitalistas. Isto atentaria abertamente com uma análise condizente com o materialismo histórico, a qual prioriza, sempre, a análise histórica e seus efeitos, sem com isso fazer prognósticos deterministas. De qualquer forma, ausenta-se em Holloway uma análise aprofundada dos alcances e

40. Luciano Cavini Martorano, “Elementos do Estado socialista na Comuna de Paris". In: Armando Boito Jr. (org.). A Comuna de Paris na história. Campinas, São Paulo, Cemarx/IFCH/UNICAMP, Xamã, 2001, p. 71. 41. Atilio Boron, "A selva e a polis...", cit., p. 220.

120 Mudar o mundo através do poder. Notas críticas às interpretações de Holloway sobre a transição 
limites dessas experiências, de modo que Löwy ressalta que uma das suas principais objeções às teses de Holloway sobre o poder, o anti-poder e o contra-poder

...é seu caráter extremamente abstrato. Ele menciona a importância da memória da resistência, mas há pouca memória, muito pouca história em sua argumentação, pouca discussão dos méritos ou limites dos movimentos revolucionários reais, marxistas, anarquistas ou zapatistas desde $1917^{42}$.

É, portanto, imprescindível que se leve em consideração tanto a construção e o desenvolvimento de uma teoria do Estado capitalista quanto a de uma teoria do Estado socialista. E é justamente uma reflexão sobre o lugar e a função do político na transição de um modo de produção ao outro que Balibar iniciou em seu texto "Conceitos fundamentais do materialismo histórico" "43. A tese defendida por esse autor é a da antecipação do político em relação à economia como a primeira etapa necessária para a transição de um modo de produção ao outro.

Ao se propor essa construção de uma teoria da transição, Balibar abandona a tese de que a transição de um modo de produção a outro ocorreria através da simples contradição entre forças produtivas e relações de produção. Se assim o fosse, a contradição seria originária e única, pois o desenvolvimento unilinear das forças produtivas seria a causa dessas transformações estruturais. Logo, caso existisse de fato uma contradição entre forças produtivas e relações de produção, a reprodução do M.P.C., por exemplo, não ocorreria. O que condiciona, então, a reprodução de um modo de produção particular é uma relação de implicação recíproca entre relações de produção e forças produtivas, pois estas se desenvolvem de acordo com relações de produção específicas do modo de produção a qual pertencem; cada modo de produção engendra, pois, suas forças produtivas específicas, expressão de suas relações de produção, existindo, portanto, uma relação de correspondência entre a sua estrutura econômica e a sua estrutura jurídico-política, justamente para que o funcionamento, a reprodução deste mesmo modo de produção, ocorra.

42. Michel Löwy, “Resenha: Mudar o mundo sem tomar o poder". In: Crítica Marxista, Rio de Janeiro, Editora Revan, no 20, abril de 2005, p. 175.

43. Étienne Balibar, “Acerca de los conceptos fundamentales del materialismo histórico”. In: Louis Althusser, Étienne Balibar, et al. Para Leer El Capital. 4a edição, Buenos Aires, Siglo XXI, 1970.

Socialismo no século XXI cadernos cemarx, n-03-2006 121 
As relações assim descobertas se implicam reciprocamente, especialmente as relações de propriedade e as relações de apropriação real ("forças produtivas") em sua unidade complexa. Compreendem os "momentos" anteriormente separados (produção, distribuição, consumo), em uma unidade necessária e completa. E, igualmente, compreendem tudo o que em curso da análise do processo de produção imediata como os seus "pressupostos", as suas "condições" necessárias para que esse processo possa realizar-se na forma que foi descrito... ${ }^{44}$.

A contradição, para Balibar, é "derivada" e não "originária", ou seja, não está presente na estrutura, mas nos efeitos da estrutura. É a sincronia - reprodução simples - ou a dinâmica - reprodução ampliada - de um modo de produção o que possibilita o surgimento dos elementos contraditórios que poderão gerar os elementos do futuro modo de produção. Balibar, pois, aponta a multiplicidade de causas que podem determinar a transição, abandonando o determinismo segundo o qual o desenvolvimento linear das forças produtivas ocasionaria, fatalmente, as transformações sociais. Logo, ao aplicarmos sua teoria da transição ao M.P.C., podemos concluir que o socialismo, de fim inevitável, passa a ser uma possibilidade condicionada a determinações histórico-sociais. Privilegia-se, nesse contexto, o papel da política - da luta de classes, da revolução política - determinado, em última instância, pelo econômico, como central na transição.

A transição só ocorre quando passar a existir uma relação de não-correspondência, no nível econômico, entre as relações de propriedade e relações de apropriação material e no nível da estrutura social a partir de um desajuste por antecipação do político frente ao econômico ${ }^{45}$.

É importante ressaltar que a antecipação do político se dá porque o desenvolvimento das forças produtivas abre possibilidades para isso e, assim, a natureza política do Estado pode ser transformada através da prática política que resulta da luta de classes. No entanto, a economia permanece vinculada às relações de produção anteriores, ou seja, em defasagem em relação ao polí-

44. Balibar, “Acerca de los conceptos...", op. cit., p. 293.

45. Os conceitos balibarianos de correspondência e não-correspondência foram melhores desenvolvidos por Boito, “O lugar da política...", op. cit., p. 76-77.

122 Mudar o mundo através do poder. Notas críticas às interpretações de Holloway sobre a transição 
tico. Portanto, a transição só ocorre se restabelecer a correspondência entre o Político e o Econômico, ou seja, se a economia se ajustar às relações políticas do novo Estado ${ }^{46}$.

Na tentativa de ressaltarmos o papel do político na transição socialista através de uma reflexão teórica sobre o Estado capitalista, cabe a pergunta: como é possível defender o rompimento com a ordem vigente sem ressaltar a necessidade da construção de um "poder-sobre" de novo tipo que garanta a transição para uma sociedade qualitativamente distinta? Gostaríamos de deixar claro que não pretendemos, por tudo o que aqui expomos, desconsiderar a importância de uma crítica às experiências do "socialismo real"; porém, isso não pode ser pretexto para o abandono de uma reflexão teórica sobre as estratégias para a ação revolucionária. E é neste sentido que Boron insiste na importância de uma reflexão teórica sobre o Estado capitalista, pois,

...por mais que alguns teóricos falem da "desestatização" ou do "descentramento" do Estado, este continuará sendo por bastante tempo um componente fundamental de nossas sociedades e o sustentáculo final de uma ordem social, que reforça com leis e instituições públicas desenvolvidas no nível do Estado o domínio dos monopólios. E mais vale contar com diagnósticos precisos acerca de sua estrutura e funcionamento e com estratégias adequadas para enfrentá-lo"47.

Ressaltamos, portanto, que ao defender que o Estado não é mais um centro de poder, Holloway passa a incorporar teses do próprio pensamento neoliberal e pós-moderno, como a do desaparecimento do capital nacional e da perda da importância territorial, cultural e política dos Estados-nações, da perda da centralidade do conceito de classe social enquanto instrumento de análise das contradições sociais e acaba por fortalecer, apesar de este não ser seu objetivo, uma

46. É importante ressaltar que o desenvolvimento da concepção que não privilegia a primazia do desenvolvimento das forças produtivas enquanto agente da transição socialista - mas que não abre mão da importância do seu desenvolvimento para a transição - só será possível a partir da experiência histórica da Revolução cultural chinesa. Veja-se, neste sentido, Charles Bettelheim, Revolução cultural e organização industrial na China. Rio de Janeiro, Edições Graal, 1979.

47. Boron, "A selva e a polis...", cit., p. 220.

Socialismo no século XXI

cadernos cemarx, n-3-2006 123 
visão que naturaliza o capitalismo e obscurece suas contradições, mesmo que esta se apresente como contra a sua atual fase neoliberal (como, por exemplo, a visão defendida pelas ONGs, pelo movimento altermundialista, etc).

Gostaríamos, pois, de ressaltar que a aposta na espontaneidade de ações contestatórias e de transformação da sociedade atual aponta para a idealização uma realidade social diferente, mas, infelizmente, não nos indica qual o caminho para a sua construção.

124 Mudar o mundo através do poder. Notas críticas às interpretações de Holloway sobre a transição 